\title{
ДОБЫЧА
}

УДК 622; https://doi.org/10.37878/2708-0080/2021-3.06

\section{ИСПОЛЬЗОВАНИЕ ГЕКСАНА ДЛЯ ПОВЫШЕНИЯ ЭФФЕКТИВНОСТИ ПАРА ПРИ ДОБЫЧЕ ВЫСОКОВЯЗКОЙ НЕФТИ}

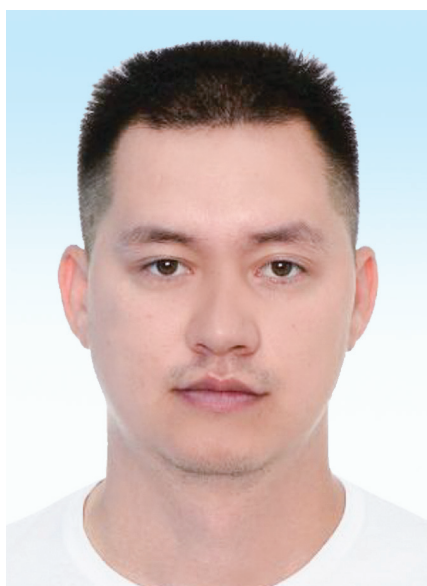

А.В. ЛОГВИНЕНКО ${ }^{1 *}$, сеньор-лектор кафедры «Неортяная инженерия»

Satbayev University, https://orcid.org/0000-0001$6621-101 X$

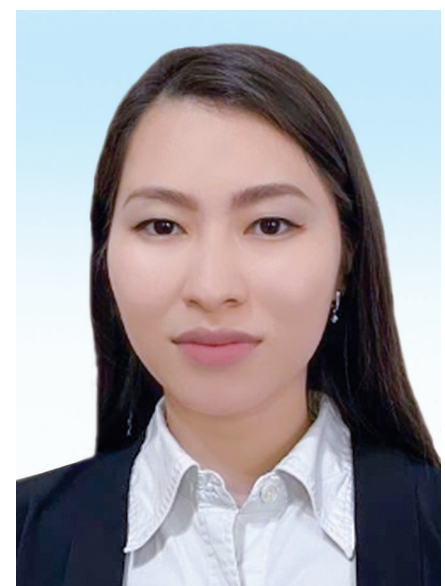

Н.Н. БАЙХАНОВА ${ }^{2}$ магистрант кафедры «Физическая химия, катализ и нефртехимия» КазНУ им. Аль-Фараби, https://orcid.org/0000-0002-

5073-6476

1SATBAYEV UNIVERSITY

Республика Казахстан, 050013, г. Алматы, ул. Сатпаева, 22а

${ }^{2}$ КАЗНУ ИМ. АЛЬ-ФАРАБИ

Республика Казахстан, 050040, г. Алматы, пр. Аль-Фараби, 71

Казахстан располагает значительным количеством месторождений с запасами высоковязкой нефтти. Большинство таких нефтей залегает на небольшой глубине - до 1000 м; их динамическая вязкость - более 1000 мПа ${ }^{*}$. В мировой практике в подобных условиях применяют хорошо зарекомендовавшие себя способы добычи: SAGD (парогравитационный дренаж нефти) и VAPEX (закачка парообразного растворителя в пласт в режиме гравитационного дренажа). В Казахстане такие технологии не применяют. $B$ работе приведены результаты лабораторных исследований изменения динамической вязкости высоковязкой нефти при смешивании её в различных соотношениях с химическим растворителем - гексаном. В мировой практике добавление гексана к закачиваемому пару приводит к наиболее значительному повышению совокупной добычи нефрти и снижению затрат на генерацию пара. Эффрективность действия гексана зависит от х фризических свойств получаемой смеси: растворитель-нефть. Гексан рекомендуется авторами в качестве добавки в малых концентрациях к основному реагенту закачки (пар, горячая вода, пропан-бутановая смесь, $\mathrm{CO}_{2}$ и др.).

КЛЮЧЕВЫЕ СЛОВА: VAPEX,Es-SAGD, динамическая вязкость, высоковязкая нефрть, гексан, растворитель.

\footnotetext{
* Адрес для переписки. E-mail: alex.kazntu@gmail.com
} 


\title{
ТҰТҚЫРЛЫҒЫ ЖОҒАРЫ МҰНАЙ ӨНДІРУ КЕЗІНДЕ БУДЫН ТИІМДІЛІГІН АРТТЫРУ ҮШІН ГЕКСАНДЫ ПАЙДАЛАНУ
}

A.В. ЛОГВИНЕНкО', Satbayev University «Мұнай инженериясы» кафедрасының сеньор-лекторы, https://orcid.org/0000-0001-6621-101X;

Н.Н. БАЙХАНОВА², Әл-Фараби атындағы ҚазҰУ «Физикалық химия, катализ және нефтехимия» кафредрасының магистранты, https://orcid.org/0000-0002-5073-6476

\author{
1SATBAYEV UNIVERSITY \\ Қазақстан Республикасы, Алматы, 050013, Сәтбаев көшесі, 22а \\ ²Ә-ФАРАБИ АТЫНДАҒЫ ҚАЗАҚ ҰЛТТЫҚ УНИВЕРСИТЕТІ \\ Қазақстан Республикасы, Алматы, 050040, Әл-Фараби даңғылы, 71
}

Қазақстанда тұтқырлығы жоғары мұнай кен орындарының айтарлықтай қорлары бар. Мұндай кен орындарының көпшілігі динамикалық тұтқырлығы 1000 мПа*С-тан асатын 1000 м-ге дейінгі таяз тереңдікте жатыр. Әлемдік тәжірибеде мұндай жағдайларда өндірудің жақсы дәлелденген әдістері қолданылады: SAGD (мұнайдың бу-гравитациялық дренажы) және VAPEX (гравитациялық дренаж режимінде буға ұқсас еріткішті қабатқа айдау). Қазақстанда мұндай технологиялар қолданылмайды. Жұмыс барысында химиялық еріткіш - гексанмен әр түрлі пропорцияда араласқан кезде тұтқырлығы жоғары мұнайдың динамикалық тұтқырлығының өзгеруінің зертханалық зерттеу нәтижелері келтірілген. Әлемдік тәжірибеде айдалатын буға гександы қосу мұнайдың жалпы өндірісінің едәуір артуына және бу генерациясының шығындарының төмендеуіне әкеледі. Гександы айдаудың тиімділігі еріткіш-мұнай қоспасының алынған физикалық қасиеттеріне байланысты. Авторлар гександы негізгі айдау реагентіне (бу, ыстық су, пропан-бутан қоспасы, $\mathrm{CO}_{2}$ және т.б.) аз концентрациядағы қоспа ретінде ұсынады.

TYЙIH СөзДЕP: VAPEX, Es-SAGD, динамикалық тұтқырлық, тұтқырлығы жоғары мұнай, гексан, еріткіш.

\section{USING HEXANE TO ENHANCE STEAM EFFICIENCY IN HIGH-VISCOSITY INDEX OIL PRODUCTION}

A.V. LOGVINENKO ${ }^{1}$, senior-lecturer at Petroleum engineering department, Satbayev University, https://orcid.org/0000-0001-6621-101X;

N.N. BAIKHANOVA ${ }^{2}$, master student at department of Physical Chemistry, Catalysis and Petrochemistry, Al-Farabi Kazakh National University, https://orcid.org/0000-0002-5073-6476

1SATBAYEV UNIVERSITY

The Republic of Kazakhstan, 22a Satbayev str., 050013, Almaty

${ }^{2}$ AL-FARABI KAZAKH NATIONAL UNIVERSITY

The Republic of Kazakhstan, 71 Al-Farabi str., 050040, Almaty

Kazakhstan has significant amount of heavy oil deposits. Most of these fields have shallow depth lower than $1000 \mathrm{~m}$ at dynamic viscosity more than $1000 \mathrm{mPa}{ }^{*} \mathrm{~s}$. In worlds practice wellproven recovery methods are used for such conditions: SAGD (steam-assisted gravity drainage) and VAPEX (vapor extraction). Such technologies are not used in Kazakhstan. The paper presents experimental results of changes the dynamic viscosity of heavy oil when blending in various proportions with chemical solvent - hexane. As according to world experience the additionofhexa netosteaminjectionleadsto the most intense of oil production total rise and cost reduction of steam 
generation. Efficiency of hexane injection depends on obtaining physical properties of solvent-oil mixture. Hexane is recommended by the authors as an additive at small concentrations to the main injection reagent (steam, hot water, propane-butane mixture, $\mathrm{CO}_{2}$ and others).

KEY WORDS: VAPEX, ES-SAGD, dynamic viscosity, heavy oil, hexane, solvent.

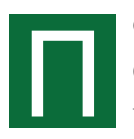

очти 90 \% всех запасов высоковязкой нефти сосредоточены в Канаде и Венесуэле [1]. В Казахстане из порядка 220 месторождений нефти и газа большая часть содержит традиционные углеводороды, извлекаемые с применением стандартных технологий; к ним отнесятся: первичные (с учетом вида пластовой энергии), вторичные (заводнение, закачка газа с целью поддержания пластового давления) и третичные, - иные методы увеличения нефтеотдачи (полимерное заводнение, термические способы и тд.). Однако в РК есть 47 месторождений с такими нефтями, которые разрабатываются только третичными методами. Эти нефти характеризуются очень высоким значением динамической вязкости, соответственно, крайне низкой подвижностью. Без снижения вязкости такую нефть невозможно извлечь на поверхность, её необходимо предварительно либо подогреть, либо привести в жидкое состояние с помощью растворителя. Для подогрева высоковязкой нефти обычно используют горячую воду, пар или газ. Для растворения - углеводородные газы или жидкости [2]. Наилучшим паровым методом считается процесс парогравитационный дренаж нефти SAGD [3]. В данной работе был использован гексан. Из-за высокой стоимости гексан широко используется в качестве незначительной добавки к закачиваемому пару ( технология Es-SAGD) с целью снижения потерь тепла через кровлю пласта; его также добавляют к закачиваемому низкоуглеводородному газу [4]. Лабораторные и расчетные исследования $[5,6]$ показали, что при закачке парогексановой смеси с содержанием гексана в количестве $1 \%$ дебит нефти увеличивается в среднем в два раза. В работе [7] при использовании добавки гексана были получены высокие значения нефтеотдачи - 90,5\%; для сравнения в технологии SAGD - 73\%. Были получены разрабатываемого компанией Тарбагатай Мунай. В связи со сложностью доставки и тестирования пластовой нефти все исследования (образцов высоковязкой нефти, керна и пластовой воды с месторождения Сарыбулак) проводились на образцах с дегазированной нефтью, плотность и вязкость которой выше.

Методология проведения исследования состояла из следующих этапов:

- измерение динамической вязкости разгазированной нефти при различных температурах $\left(40-80^{\circ} \mathrm{C}\right)$ и атмосферном давлении на вискозиметре Штабингера;

- измерение динамической вязкости смеси разгазированной нефти и жидких растворителей в различных пропорциях при пластовой температуре и атмосферном давлении на вискозиметре Штабингера.

Замеры вязкости производились по 4 раза для каждого образца и вычислялись среднее арифметическое значение.

Научными результатами исследования является получение зависимостей динамической вязкости смеси нефть-растворитель от концентрации растворителя - гексана. 
Экспериментальные исследования динамической вязкости дегазированной нефти и растворителей. Согласно методу VAPEX вытеснение высоковязкой нефти из пластов с использованием химических растворителей, имеет место не вытеснение нефти, а ее растворение при смешивании с парообразным и/или жидким растворителем, при этом получаемая смесь с пониженной вязкостью стекает в нижнюю добывающую скважину [8].

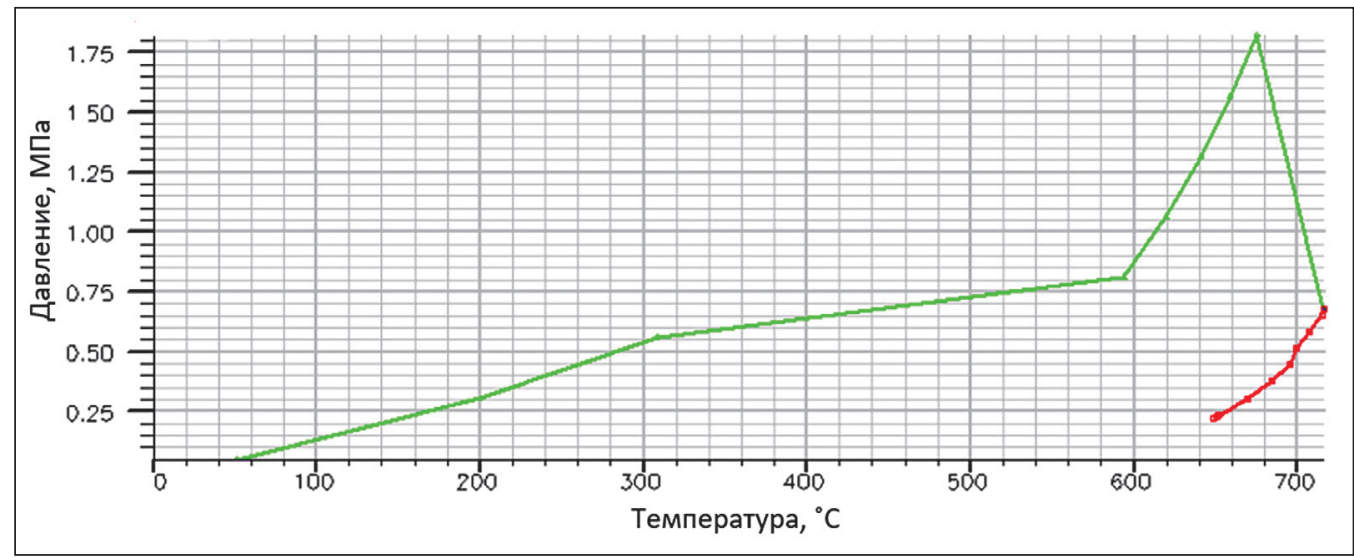

Рисунок 1 - Фазовая диаграмма разгазированной нефти

На рисунке 1 представлена фазовая диаграмма разгазированной высоковязкой нефти с месторождения Сарыбулак. Зеленой линией отмечена граница раздела однофазной (жидкость) и двухфазной (жидкость-газ) областей. Красной линией также отмечена граница между двухфазной (жидкость-газ) и однофазной (газ) областями. При пластовых условиях (Рпл $=13,6 \mathrm{MПа,} \mathrm{tпл}=40^{\circ} \mathrm{C}$ ) данный образец нефти будет находиться в однофазном, жидком состоянии, а для того чтобы превратить такую нефть в газ, необходимо повысить пластовую температуру минимум до $650^{\circ} \mathrm{C}$, оставаясь в низком диапазоне давлений (ниже 0,75 МПа).

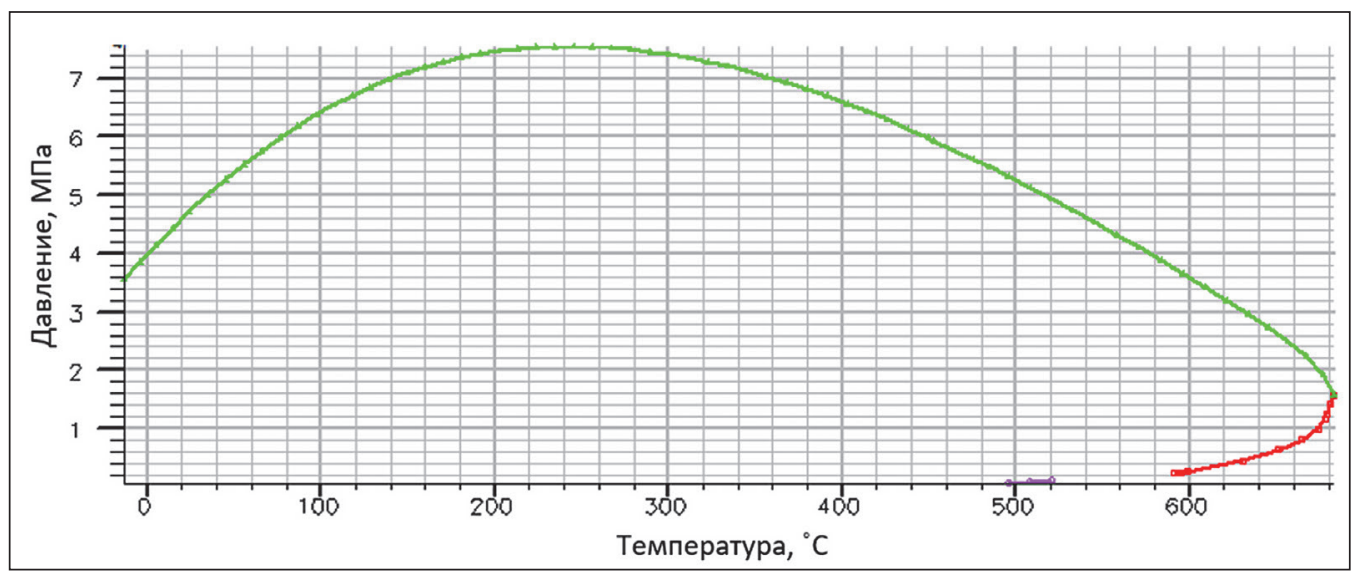

Рисунок 2 - Фазовая диаграмма пластовой нефти 


\section{ДОБЫЧА}

На рисунке 2 представлена фазовая диаграмма пластовой высоковязкой нефти с месторождения Сарыбулак. Зеленой линией отмечена граница раздела однофазной (жидкость) и двухфазной (жидкость-газ) областей. Красной линией также отмечена граница между двухфазной (жидкость-газ) и однофазной (газ) областями. При пластовых условиях (Рпл $=13,6 \mathrm{MПа,} \mathrm{tпл}=40^{\circ} \mathrm{C}$ ) данная нефть будет также находиться в однофазном, жидком состоянии, так как для того чтобы газ начал выделяться из нефти необходимо будет при пластовой температуре в $40^{\circ} \mathrm{C}$ достичь пониженного давления 5 МПа. Такие условия возможны скорее всего только в скважине. В однофазном газовом состоянии такая нефть будет при низких давлениях (ниже $1,75 \mathrm{MПа)} \mathrm{и} \mathrm{высоких} \mathrm{температурах} \mathrm{(более} 600^{\circ} \mathrm{C}$ ).

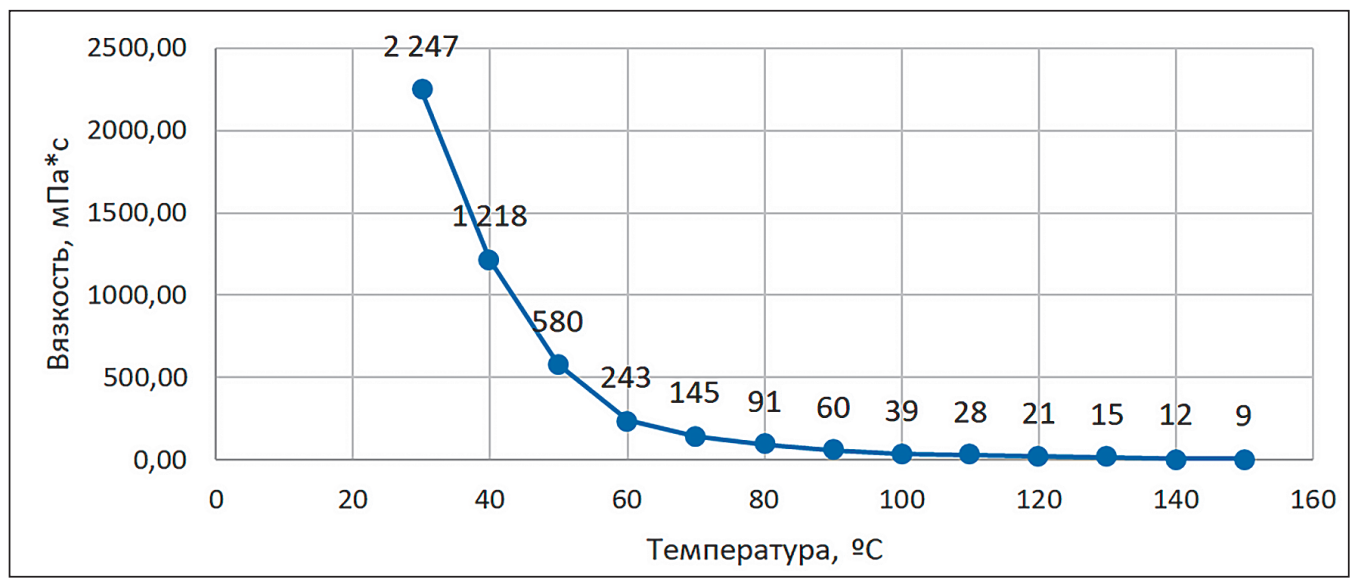

Рисунок 3 - Зависимость вязкости нефрти от температуры

На рисунке 3 представлены результаты лабораторных исследований ВВН месторождения Сарыбулак. Исследования проводились на вискозиметре Штабингера при атмосферном давлении. Диапазон исследований составил от 30 до $150^{\circ} \mathrm{C}$. При таком нагреве вязкость резко снижалась с 2247 до 9,3 мПа*с, что в свою очередь говорит о положительном влиянии тепловых методов на нефть месторождения Сарыбулак. Из рисунка 3 можно сделать вывод, что нет необходимости повышать температуру свыше $150^{\circ} \mathrm{C}$, так вязкость будет изменяться незначительно.

На рисунке 4 представлена зависимость температуры от давления насыщенного пара, сделанная по паровым таблицам. Область выше линии насыщения соответствует жидкой фазе. Область ниже линии насыщения соответствует паровой фазе. При пластовом давлении 13,6 МПа температура, при которой вода будет находиться в паровой фазе, будет равна $335^{\circ} \mathrm{C}$. Это означает, что только при температуре свыше $335^{\circ} \mathrm{C}$ мы получим нагнетаемый пар. В связи с этим следует, что генерация пара такого качества будет весьма затратным делом. Поэтому замена технологии закачки пара на метод VAPEX является логичным выбором.

На рисунке 5 описываются условия проведения эксперимента по определению вязкости дегазированной нефти при 0,1 МПа. 


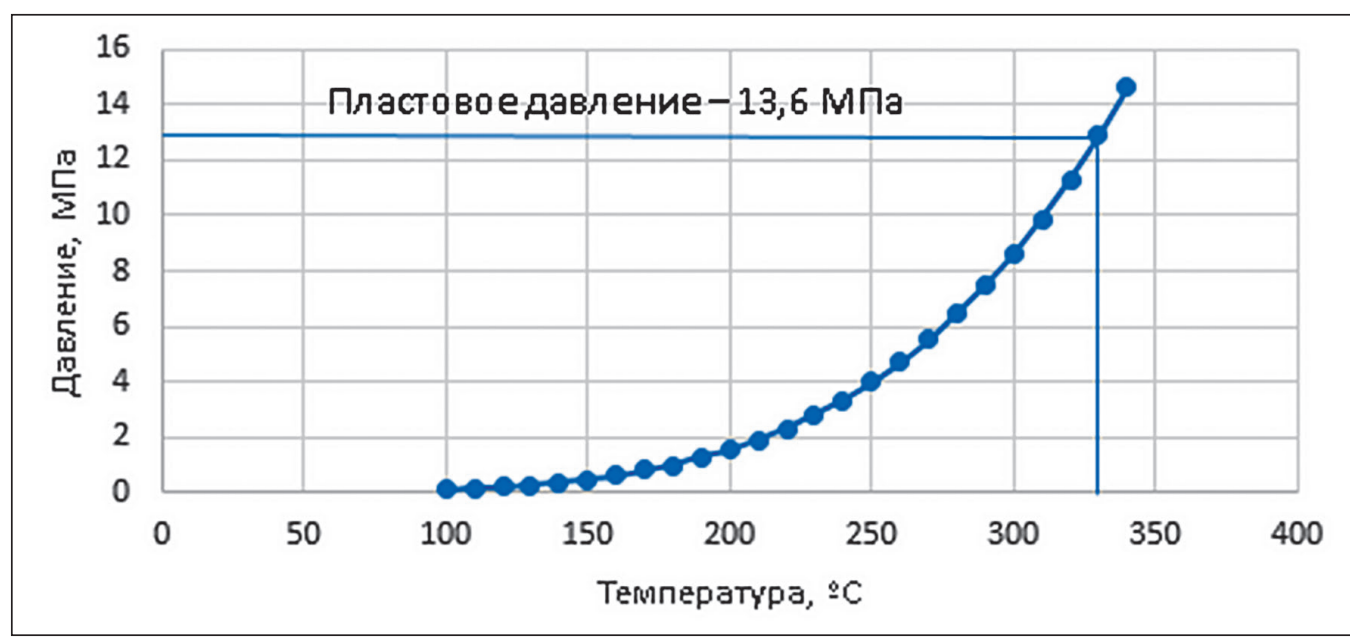

Рисунок 4 - Зависимость температуры от давления насыщенного пара

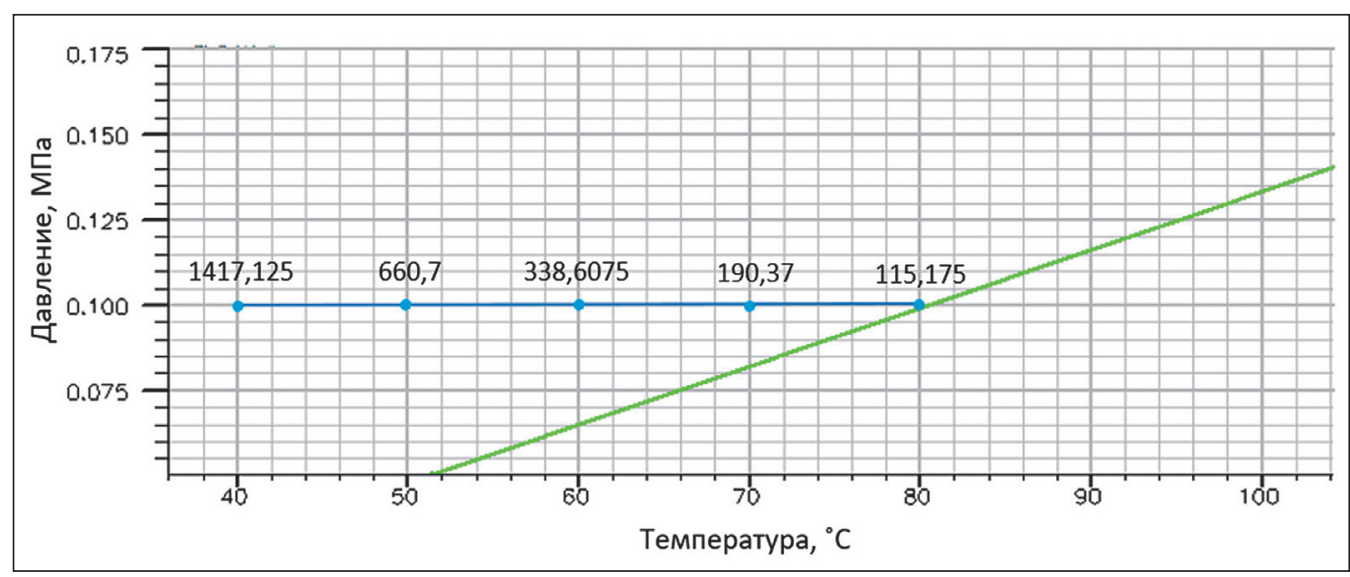

Рисунок 5 - Динамическая вязкость разгазированной нефти в зависимости от температуры при атмосферном давлении

На рисунке 6 представлены результаты измерения динамической вязкости смеси разгазированной нефти и гексана от концентрации гексана. Гексан является наилучшим растворителем по результатам многих работ $[9,10]$. При пропорциях 1:1 вязкость нефти падает с 2247 до 0,4 мПа* с при температуре $40^{\circ} \mathrm{C}$, т.е. уменьшается в 5600 раз. Вязкость гексана составляет 0,253 мПа*с при температуре $40^{\circ} \mathrm{C}$. Так как динамическая вязкость не является аддитивным свойством, то наиболее точным способом ее расчета будет экспериментальное определение. В наименьших пропорциях нефти к гексану 10:1 вязкость падает до значений 236,1 мПа*с, то есть почти в 10 раз.

\section{ВЫВОДЫ}

Гексан обладает высокой растворяющей способностью и легко смешивается с нефтью. Небольшое содержание гексана в закачиваемом реагенте способно значи- 


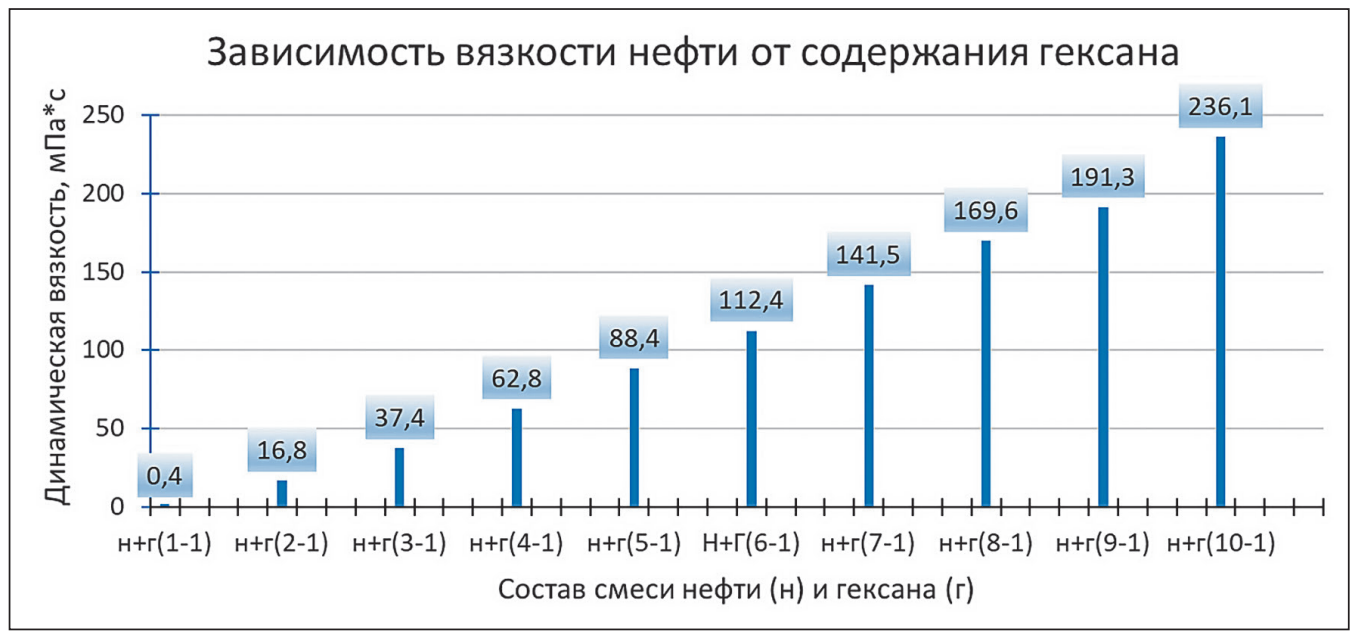

Рисунок 6 - График зависимости динамической вязкости смеси разгазированной нести и гексана от содержания гексана

тельно снизить динамическую вязкость нефти, увеличивая подвижность пластового флюида. При пластовом давлении и температуре гексан будет находиться в жидком состоянии. В случае закачки горячей воды, гексан также будет находиться в жидком состоянии. Температура горячей воды при этом не должна превышать $100^{\circ} \mathrm{C}$. При температуре $150^{\circ} \mathrm{C}$ вязкость дегазированной нефти снижается до 9 мПа*с. Чтобы закачать пар при пластовом давлении, необходимо достичь температуры на забое в $335-340^{\circ} \mathrm{C}$, что экономически невыгодно, а между тем основные затраты при паровых методах как раз обусловлены генерацией пара. В этом случае добавление гексана позволит значительно снизить паронефтяное отношение, что приведет к существенному сокращению затрат на генерацию пара, а также росту совокупной добычи нефти за счет дополнительного механизма снижения динамической вязкости пластового флюида. Окончательное решение о выборе метода добычи нефти, химических добавок и т.д. должно основываться на сравнении гидродинамических моделей различных вариантов методов увеличения нефтеотдачи, подтвержденных экспериментально, а также проведения технико-экономического обоснования каждого варианта.

\section{ЛИТЕРАТУРА}

1 U.S. Department of Energy. Country Analysis Brief: Canada/ //Energy Information Administration of the U.S. Department of Energy, 2007. - PP. 161-180.

2 ConocoPhillips. Технология добычи «тяжелой» нефти. Евразийский энергетический форум.- Астана, 2008. - 2-4 с. [ConocoPhillips. Tekhnologiya dobychi «tyazheloy» nefti. Yevraziyskiy energeticheski forum. - Astana, 2008. - 2-4 s.]

3 ButlerR.M., McnabG.S., and LoH.Y. Theoretical studies on the Gravity Drainage of Heavy Oil During In-Situ Steam Heating/ //Canadian Journal of Chemical Engineering - Wiley, 1981. - Vol. 59, Issue4. - PP. 6.

4 Weiqiang Li. Improved steam assisted gravity drainage (SAGD) performance with solvent as steam additive/ //Texas A\&M University - PhD Thesis, 2010. PP. 88-89.

5 NasrT.N., BeaulieuG., GoldbeckH., HeckG.Novel Expanding Solvent-SAGD Process "ESSAGD"/ //Journal of Canadian Petroleum Technology - SPE, 2003. - Vol. 42, No. 1. -PP. 13-16. 


\section{ДОБЫЧА}

6 McCormack M.E. Design of Steam-Hexane Injection Wells for Gravity Drainage Systems/ //Journal of Canadian Petroleum Technology - SPE, 2005. - Vol. 48, No. 1. - PP. 23-26.

7 Souraki Y., Ashrafi M., Jahanbani Ghahfarokhi, Torsaeter O. Application of Solvent Alternating SAGD Process to Improve SAGD Performance in Athabasca Bitumen Reservoir/ //The SPE Western Regional and AAPG Pacific Section Meeting, Joint Technical Conference - SPE, 2013. - PP. 4-8.

8 Butler R.M., Mokrys I.J. A New Process (VAPEX) for Recovering Heavy Oils Using Hot Water and Hydrocarbon Vapour/ //Journal of Canadian Petroleum Technology - SPE, 1991. - Vol. 30, No. 1. - PP. 97-105.

9 Moslem Hosseininejad Mohebati, Brij B. Maini, Thomas G. Harding. Experimental Investigation of the Effect of Hexane on SAGD Performance at Different Operating Pressures/ //SPE Heavy Oil Conference Canada - SPE, 2012. - PP. 3-6.

10 McCormack M.E. Design of Steam-Hexane Injection Wells for Gravity Drainage Systems. Society of Petroleum Engineers (SPE)/ //Journal of Canadian Petroleum Technology- SPE, 2009. - Vol. 48, No. 1. - PP. 25-27. 